\title{
Chemosynthesis-based associations on Cretaceous plesiosaurid carcasses
}

Andrzej Kaim, Yoshitsugu Kobayashi, Hiroki Echizenya, Robert G. Jenkins, and Kazushige Tanabe Acta Palaeontologica Polonica 53 (1), 2008: 97-104 doi:http://dx.doi.org/10.4202/app.2008.0106

The objective of this report is to document first Mesozoic occurrences of chemosynthesis-based communities developed on large marine reptile carcasses. Micro-grazing provannid gastropods (typical of chemosynthetic communities) are associated with plesiosaurid skeletons in the Upper Cretaceous deposits of Hokkaido, northern Japan. The cancellous bones of the examined plesiosaurid bones contain a ubiquity of iron sulfides within the bone trabeculae, which provides evidence of anaerobic sulfate reduction of the bone lipids. We also report numerous microborings in the bone trabeculae, which might result from the activity of sulfur-oxidizing bacteria. This finding addresses the hotly debated problem of the emergence and radiation of whale bone faunas. We postulate that vertebrate bone environments in the Northwest Pacific region were settled repeatedly by animals from a regional pool of chemosynthesis-based communities that flourished in the methane seeps and/or hot vents that were present during the Late Cretaceous-Miocene.

Key words: Plesiosauridae, Provannidae, vertebrate-bone community, chemosynthetic community, Cretaceous, Japan.

Andrzej Kaim kaim@twarda.pan.pl, Instytut Paleobiologii PAN, ul. Twarda 51/55, 00-818 Warszawa, Poland and Department of Earth and Planetary Science, University of Tokyo, 7-3-1 Hongo, Bunkyo-ku, Tokyo, 113-0033, Japan; Yoshitsugu Kobayashi ykobayashi@museum.hokudai.ac.jp and Hiroki Echizenya etizen@ museum.hokudai.ac.jp, Hokkaido University Museum, Kita 10, Nishi 8, Kita-ku, Sapporo, Hokkaido, 060-0810, Japan; Robert G. Jenkins robert@eps.s.u-tokyo.ac.jp and Kazushige Tanabe tanabe@eps.s.u-tokyo.ac.jp, Department of Earth and Planetary Science, University of Tokyo, 7-3-1 Hongo, Bunkyo-ku, Tokyo, 113-0033, Japan.

This is an open-access article distributed under the terms of the Creative Commons Attribution License (for details please see creativecommons.org), which permits unrestricted use, distribution, and reproduction in any medium, provided the original author and source are credited. 
For 5 Full text $(877.1 \mathrm{kB})$ 